\title{
PELATIHAN MEMBUAT MEDIA PEMBELAJARAN INTERAKTIF BERBASIS TEKNOLOGI INFORMASI
}

\author{
Indah Purnama Sari ${ }^{1)}$, Maemunah Nurmaya Sari' ${ }^{2)}$,Zaeni Miftah ${ }^{3)}$
}

${ }^{1,2}$ Pendidikan Ekonomi, FIPPS, Universitas Indraprasta PGRI

${ }^{3}$ Teknik Informatika, STMIK Eresha

\begin{abstract}
Abstrak
Dengan berkembangnya teknologi pada saat ini guru dapat menggunakan alat bantu media audio visual dalam proses pembelajarannya. Hal ini dilakukan untuk menghindari verbalisme yang mungkin terjadi jika hanya menggunakan alat bantu visual saja. Kegiatan pengabdian kepada masyarakat ini bertujuan untuk membantu para guru dalam menghadirkan alat bantu belajar media audio visual berbasis teknologi informasi. Output yang ingin dihasilkan dari kegiatan ini adalah kemampuan guru dalam membuat media pembelajaran interaktif. Para guru dalam kegiatan ini mendapatkan pelatihan menggunakan microsoft powerpoint dengan macro untuk menyajikan media pembelajaran interaktif yang menarik. Dengan menggunakan media pembelajaran interaktif akan dapat mengatasi sikap pasif siswa dan menimbulkan gairah belajar. Tentu saja tujuan akhir dari kegiatan ini adalah prestasi belajar siswa akan semakin meningkat. Hasil kegiatan menunjukkan antusiasme para guru dalam mempelajari Ms PowerPoint dengan macro. Proses pelatihan memakan waktu yang cukup panjang hampir 6 jam, dikarenakan para guru sebagian masih awam dengan Ms. PowerPoint sehingga proses membuat template slide cukup lama. Tim memandu peserta satu-persatu agar bisa menyelesaikan latihan sesuai dengan instruksi instruktur pelatihan. Para guru berharap pelatihan bisa dilanjutkan secara berkesinambungan karena merasakan manfaat yang besar dari diadakannya pelatihan ini.
\end{abstract}

Keywords: pelatihan, media pembelajaran, interaktif, ms. powerpoint

\begin{abstract}
With the development of technology at this time the teacher can use audio visual media tools in the learning process. This is done to avoid verbalism that might occur if only using visual aids. The community service activity aims to assist teachers in presenting information technology-based audio visual media learning aids. The output to be generated from this activity is the teacher's ability to create interactive learning media. The teachers in this activity received training using Microsoft Powerpoint with macros to present interesting interactive learning media. By using interactive learning media will be able to overcome the passivity of students and cause learning passion. Of course the final goal of this activity is that student learning achievements will increase. The results of the activity showed the enthusiasm of the teachers in learning Ms PowerPoint with macros. The training process took quite a long time, almost 6 hours, because the teachers were still partially unfamiliar with Ms. PowerPoint so the process of creating a slide template is long enough. The team guides participants one by one so they can complete the training according to the training instructor's instructions. The teachers hope the training can be continued on an ongoing basis because they feel the great benefits of holding this training.
\end{abstract}

Keywords: Training, Learning Media, Interactive, Ms. Power point

Correspondence author: Indah Purnama Sari, indahps.unindra@gmail.com, Indonesia 


\section{PENDAHULUAN}

Pembelajaran adalah sebuah proses komunikasi antara pembelajar, pengajar dan bahan ajar. Komunikasi tidak akan berjalan tanpa bantuan sarana penyampai pesan atau media. Untuk menyampaikan pesan pembelajaran dari guru kepada siswa, biasanya guru menggunakan alat bantu mengajar (teaching aids) berupa gambar, model, atau alat-alat lain yang dapat memberikan pengalaman konkrit, motivasi belajar, serta mempertinggi daya serap. Alat bantu ini dikenal dengan istilah alat bantu media visual.

Dengan berkembangnya teknologi pada saat ini guru juga menggunakan alat bantu media audio visual dalam proses pembelajarannya. Hal ini dilakukan untuk menghindari verbalisme yang mungkin terjadi jika hanya menggunakan alat bantu visual saja.

Ketika mengkaji masalah hambatan-hambatan komunikasi dalam proses pembelajaran, hambatan tersebut diantaranya: 1) verbalisme, dimana sisiwa dapat menyebutkan kata tetapi tidak mengetahui artinya, 2) salah tafsir, dimana istilah atau kata yang sama diartikan berbeda oleh siswa, 3) perhatian tidak terpusat akibat berbagai hal seperti siswa melamun, pembelajaran atau guru tidak menarik, membosankan, 4) tidak terjadinya pemahaman artinya kurang memiliki kebermaknaan baik logis maupun psikologis.

Pengembangan media pembelajaran hendaknya diupayakan untuk memanfaatkan kelebihan-kelebihan yang dimiliki oleh media tersebut dan berusaha menghindari hambatan-hambatan yang mungkin muncul dalam proses pembelajaran. Pengembangan media pembelajaran hasil teknologi baru tidak perlu dikhawatirkan menyebabkan dehumanisasi sebagaimana pandangan beberapa tokoh (Lestari, 2015). Justru sebaliknya, pengembangan media berbasis teknologi memberikan pilihan bagi siswa untuk menikmati pembelajaran yang lebih sesuai dengan karakteristik pribadinya karena walaupun berbasis teknologi, guru tetap mengajar dengan pendekatan humanis.

Kemajuan ilmu pengetahuan dan teknologi khususnya teknologi informasi sangat berpengaruh terhadap penyusunan dan implementasi strategi pembelajaran. Melalui kemajuan tersebut, para guru dapat menggunakan berbagai media sesuai dengan kebutuhan dan tujuan pembelajaran. Dengan menggunakan media komunikasi bukan saja dapat mempermudah dan mengefektifkan proses pembelajaran, akan tetapi juga bisa membuat proses pembelajaran lebih menarik (Sanjaya, 2013). Dengan kata lain, media komunikasi dalam proses pembelajaran pada hakikatnya adalah media pembelajaran.

Kegiatan pengabdian kepada masyarakat ini bertujuan untuk membantu para guru dalam menghadirkan alat bantu belajar media audio visual berbasis teknologi informasi. Output yang ingin dihasilkan dari kegiatan ini adalah kemampuan guru dalam membuat media pembelajaran interaktif. Para guru akan mendapatkan pelatihan menggunakan microsoft powerpoint untuk menyajikan media pembelajaran interaktif yang menarik. Dengan menggunakan media pembelajaran interaktif akan dapat mengatasi sikap pasif siswa dan menimbulkan gairah belajar. Tentu saja tujuan akhir dari kegiatan ini adalah prestasi belajar siswa akan semakin meningkat.

Di era globalisasi ini masih ditemukan model guru yang belum mampu beradaptasi dengan perkembangan teknologi. Masih ditemukan guru yang belum bisa menggunakan komputer. Permasalahan yang terjadi hampir di setiap sekolah adalah guru kurang kreatif dalam menyajikan media pembelajaran. 
Media pembelajaran dan metode pembelajaran yang monoton dikhawatirkan akan menimbulkan kebosanan pada diri siswa sehingga materi tidak terserap dengan baik. Dalam hal ini guru memerlukan pembinaan atau pelatihan untuk dapat menggunakan teknologi informasi beserta seperangkat alat-alatnya dengan baik dan tepat guna, khususnya untuk membuat media pembelajaran yang lebih interaktif dan menarik.

Berdasarkan hasil pertemuan awal dengan Kepala Sekolah, diputuskan bahwa persoalan prioritas yang disepakati untuk diselesaikan selama pelaksanaan program pengabdian kepada masyarakat adalah mengenai upaya meningkatkan kemampuan guru dalam menggunakan teknologi informasi, sehingga mampu membuat media pembelajaran audiovisual yang interaktif dan menarik.

\section{METODE PELAKSANAAN}

Peserta dalam kegiatan pengabdian masyarakat ini adalah semua guru-guru yang masih aktif mengajar di MI Ar-Ridha. Jumlah guru yang mengkuti pelatihan ini sebanyak 18 orang (semua guru aktif di MI Ar-Ridha mengikuti pelatihan).

Kegiatan pengabdian masyarakat dalam bentuk pelatihan membhuat media pembelajaran interaktif berbasis teknologi informasi ini dipersiapkan untuk dilaksanakan dalam jangka waktu tiga bulan, mulai dari bulan Oktober 2018 sampai dengan bulan Desember 2018. Pelaksanaan pelatihan dilaksanakan pada hari selasa, 27 November 2018 dimulai Pk. 09.00 berakhir pukul 15.00 WIB.

Metode pendekatan yang akan digunakan untuk menyelesaikan masalah guru yang belum bisa memanfaatkan teknologi informasi dengan maksimal adalah melalui pelaksanaan pelatihan. Secara rinci, metode pendekatan dijabarkan sebagai berikut:

1. Observasi

Metode observasi dilakukan untuk mendapatkan informasi mengenai berbagai media pembelajaran yang tersedia dan dimanfaatkan oleh para guru di MI ArRidha. Melalui metode ini diperoleh data bahwa sekolah memiliki sarana infocus, namun belum dimanfaatkan secara optimal oleh para guru.

2. Diskusi

Diskusi dilakukan untuk membahas mengenai solusi dari permasalahan belum maksimalnya media pembelajaran digunakan di dalam kelas. Diskusi ini terjadi antara Pengusul dengan mitra kegiatan, yaitu Kepala Sekolah MI Ar-Ridha. Dari diskusi ini diperoleh solusi untuk permasalahan yaitu akan dilaksanakan kegiatan pelatihan membuat media pembelajaran audiovisual yang interaktif berbasis teknologi informasi.

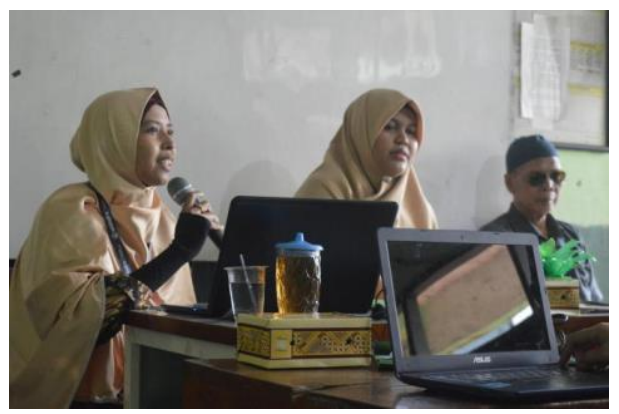

Gambar 1. Brainstorming 
3. Dokumentasi

Dokumentasi dalam kegiatan ini dilakukan untuk memperoleh data-data fisik yang berhubungan dengan sarana prasarana yang mendukung terlaksananya kegiatan ini, seperti jumlah Infocus, jumlah komputer atau laptop, data guru, dan sebagainya.

4. Presentasi

Presentasi dilakukan untuk memaparkan teori mengenai Microsoft Powerpoint, bagaimana cara menggunakan Microsoft Powerpoint, dan pengenalan berbagai fitur atau icon yang dapat digunakan

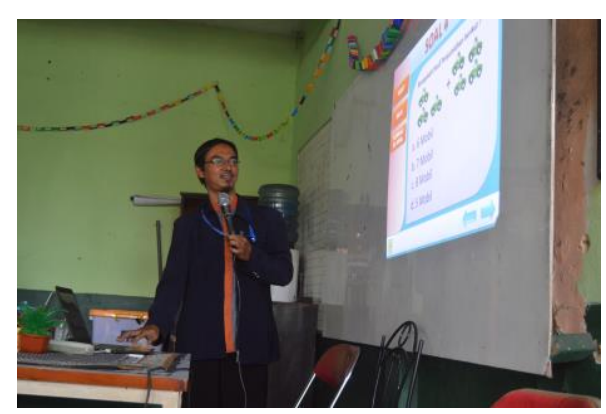

Gambar 2. Pemaparan Materi

5. Praktek

Tidak sekedar mendengarkan teori, guru juga langsung mencobanya di laptop masing-masing, misal bagaimana membuat aneka tulisan yang berwarna-warni, tulisan berjalan, berkedap-kedip, efek background, efek suara, efek perpindahan layar, insert gambar, insert video, tombol home, tombol next, tombol prev, melihat skor nilai kuis, dan sebagainya.

Pelatihan diselenggarakan sehari, dari pagi hingga selesai. Pelatihan dimulai Pk. 09.00 dan berakhir Pk. 15.00, bertempat di ruang kelas 6. Peserta selain mendapatkan teori tentang Microsoft Powerpoint, juga langsung praktik membuat media pembelajaran interaktif menggunakan Microsoft Powerpoint dengan Macro.

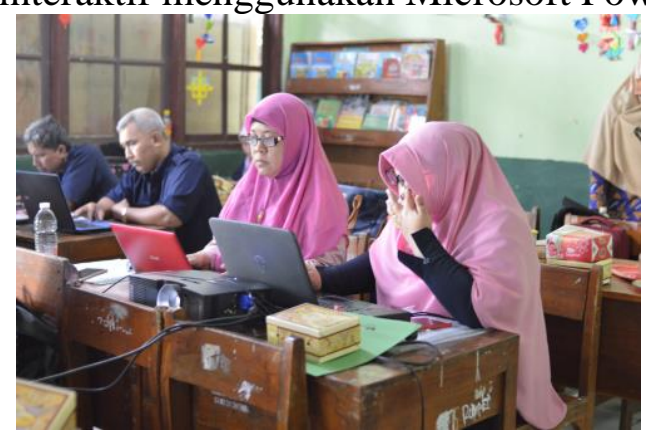

Gambar 3. Praktik

\section{HASIL DAN PEMBAHASAN}

\section{Pelaksanaan}

Kegiatan pengabdian kepada masyarakat ini dimulai sejak penjajakan ke sekolah pada awal semester gasal 2018/2019. Tim mengunjungi calon sekolah mitra, silaturahmi dengan Kepala Sekolah dan dewan guru. Tim juga berkesempatan untuk mengobservasi 
sarana dan prasarana sekolah serta tingkat kemampuan para guru dalam proses pembelajaran menggunakan sarana teknologi informasi.

Hari H disepakati dilaksanakan pada hari Selasa, 27 November 2018, dimulai Pk. 09.00. Adapun berapa lama waktu yang butuhkan tidak dibicarakan, pihak sekolah menyerahkan sepenuhnya kepada tim pengabdian kepada masyarakat. Disepakati pula bahwa semua guru aktif di MI Ar-Ridha sebanyak 18 orang diwajibkan mengikuti pelatihan ini oleh Kepala MI Ar-Ridha.

Hari Selasa, 27 November 2018 pukul 08.00 pagi para guru sudah siap menanti tim di ruang guru. Tepat jam 09.00 para guru mulai memasuki ruangan pelatihan. Jam 09.30 acara secara resmi dimulai. Tim membuka acara dan memperkenalkan diri serta menjelaskan tujuan kegiatan pelatihan. Acara dilanjutkan dengan serah terima MoU antara sekolah dengan Fakultas IPPS yang diwakili oleh ketua tim pengabdian kepada masyarakat, serta serah terima sertifikat untuk peserta secara simbolis diwakili oleh Kepala Sekolah.

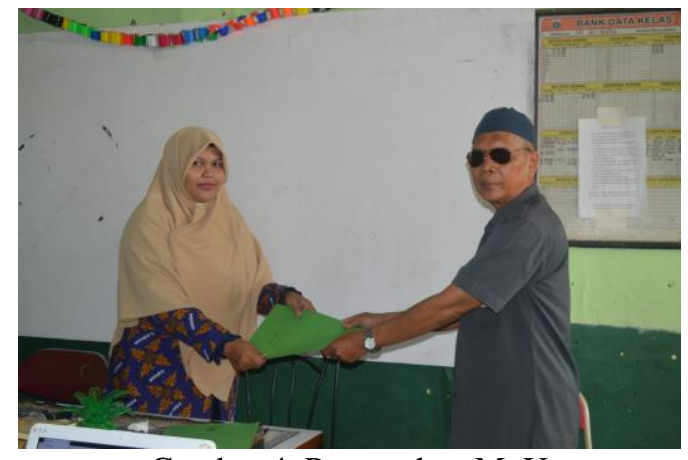

Gambar 4. Penyerahan MoU

Acara kemudian dilanjutkan dengan pemaparan oleh instruktur. Awalnya instruktur menjelaskan pentingnya penggunaan media interaktif dalam pembelajaran, salah satunya untuk meningkatkan antusiasme dan minat belajar peserta didik. Instruktur kemudian langsung memberikan contoh aplikasi media yang akan dipelajari pada kegiatan pelatihan. Instruktur mengajukan soal kuis matematika untuk siswa kelas 1 SD. Soal kuis ini dibuat interaktif, dimana siswa yang mengerjakan matematika dibuat berinteraksi dengan komputer, dan bisa langsung melihat skor hasil belajarnya. Para peserta pelatihan sangat antusias dengan bentuk kuis yang baru dan memang hal ini adalah pengetahuan baru bagi para peserta.

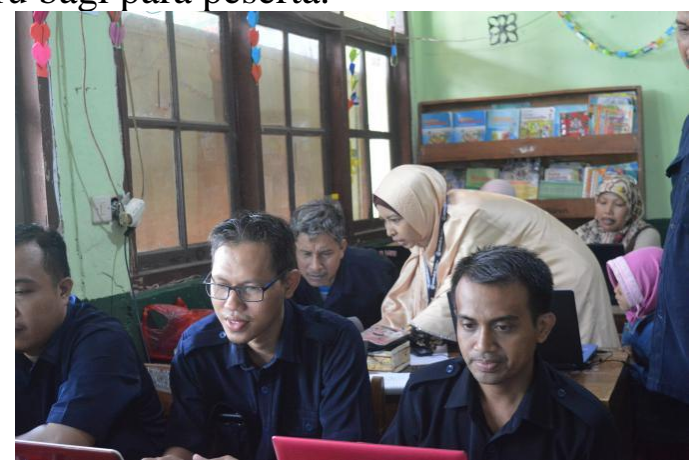

Gambar 5. Pendampingan oleh Tim 


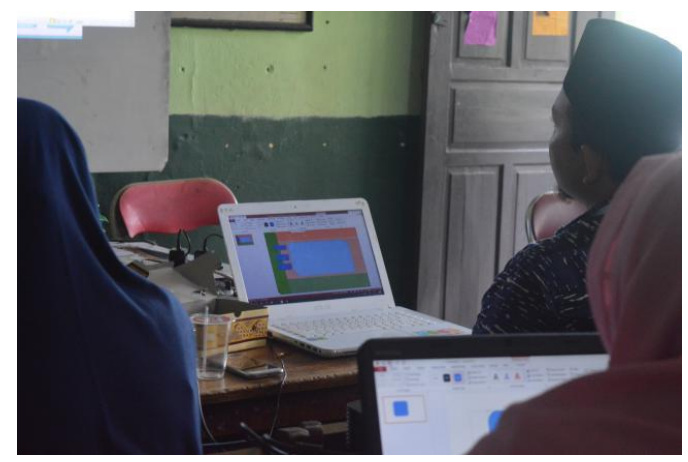

Gambar 6. Hasil Praktik

\section{Kendala}

Mengingat kemampuan awal peserta dalam hal interaksi dengan komputer sangat beragam, maka dalam pelaksanaan pelatihan ditemukan beberapa kendala, seperti :

1. Laptop yang dibuka peserta tidak dapat menampilkan Ms Powerpoint. Setelah dianalisis ternyata diakibatkan laptop tersebut menggunakan software bajakan. Oleh karenanya peserta tidak bisa mengikuti latihan praktik.

2. Laptop tidak support dengan Ms Powerpoint, memerlukan instal ulang, akibatnya peserta tidak dapat mengikuti sesi latihan praktik.

3. Layar laptop rusak, ada noda hitam yang cukup besar sehingga menyulitkan peserta untuk melihat icon-icon.

4. Peserta sama sekali belum pernah membuka dan menggunakan Ms Powerpoint, selama ini hanya berinteraksi dengan Ms Word dan Ms Excel.

5. Peserta sangat awam dengan laptop. Bahkan dalam hal menggerakkan kursor peserta mengalami kesulitan, dimana tangan belum luwes. Hal ini dialami oleh guru yang relatif senior berdasarkan usia.

6. Peserta lupa membawa charger sehingga ketika baterai habis, laptop mati dan peserta tidak dapat melanjutkan praktik.

7. Peserta tidak fokus dan sering ketinggalan perintah/instruksi dari instruktur. Hal ini disebabkan perhatian peserta yang tidak maksimal, yaitu sering mengobrol dengan rekan sebelahnya.

8. Peserta yang telah mengerti seringkali dipanggil oleh rekannya (peserta lain) untuk membantu mereka yang ketinggalan dalam mengikuti instruksi. Hal ini menyebabkan peserta yang relatif bisa mengikuti tersebut menjadi ketinggalan.

9. Jumlah instruktur dan pendamping pelatihan kurang banyak.

10. Alokasi waktu untuk pelatihan kurang, seharusnya sehari penuh.

11. Tim tidak memberikan handbook dalam bentuk print out tapi softcopy, hal ini dirasa kurang praktis.

Demikian beberapa kendala yang ditemukan dalam pelaksanaan pelatihan yang menjadi bahan acuan untuk penyelenggaraan pelatihan selanjutnya. Untuk mengetahui kritik, saran, dan usulan peserta pelatihan, tim pengabdian kepada masyarakat menyebarkan mini kuesioner. Dari 18 minikuesioner yang disebarkan, terdapat 14 minikuesioner yang kembali. Semua kuesioner menyatakan puas dan berharap pelatihan ini dapat dilanjutkan di kemudian hari. Usulan pelatihan yang akan datang misalnya tips membuat raport secara komputerisasi, pelatihan matematika, pelatihan internet, dan pelatihan lanjutan tentang Ms Powerpoint. 
Pada akhir acara tim memilih peserta terbaik dan memberikan doorprize berupa paket data $3 \mathrm{~Gb}$. Kategori peserta terbaik berdasarkan keaktifan selama pelatihan dan kecepatan dalam menyelesaikan soal latihan.

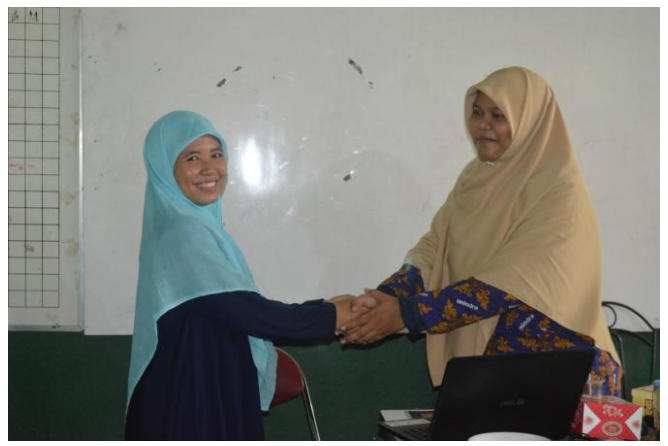

Gambar 7. Peserta Pelatihan terbaik

Seluruh peserta pelatihan mendapatkan sertifikat yang ditandatangani oleh ketua tim dan Dekan FIPPS.

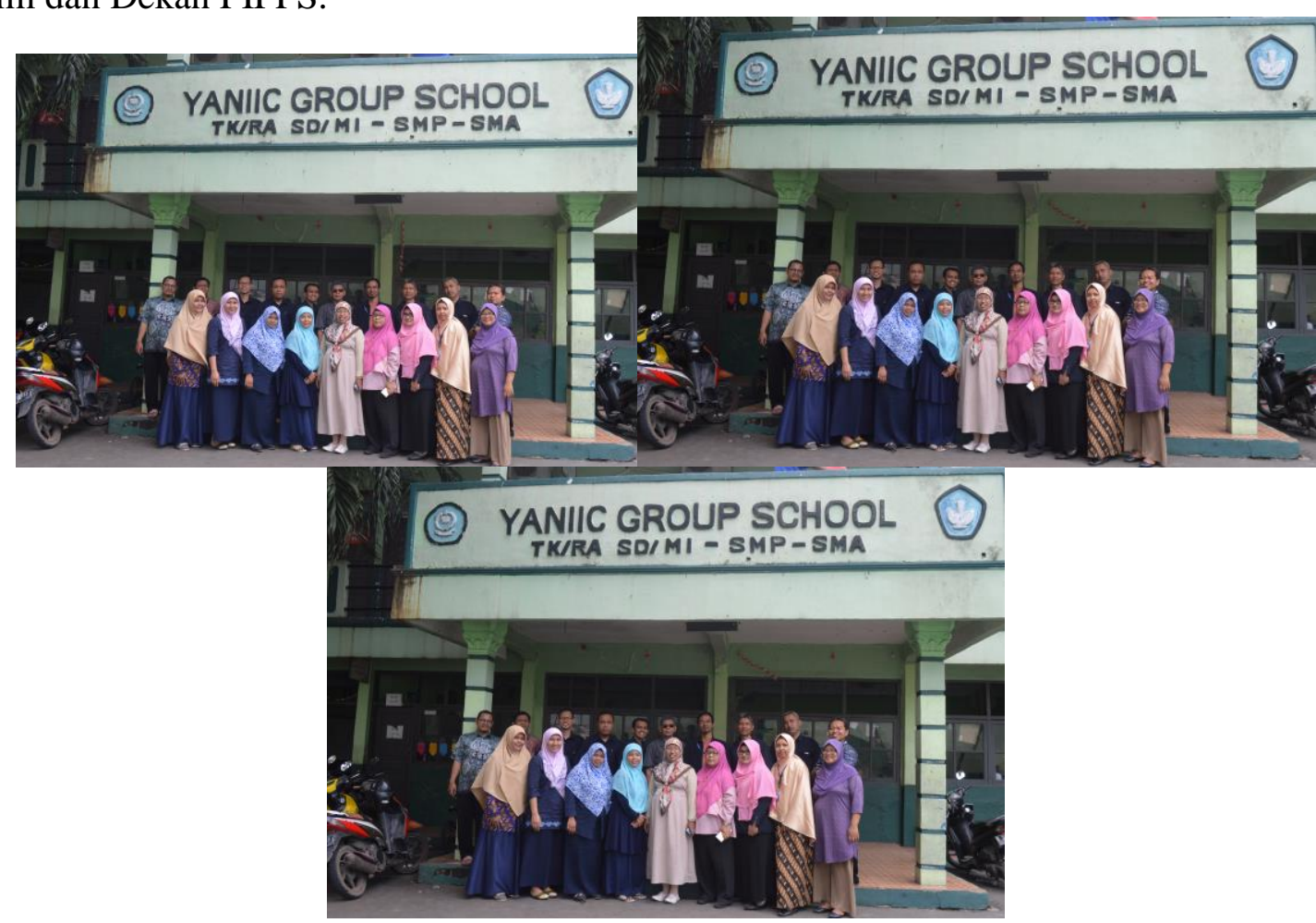

Gambar 8. Foto Bersama Tim-Peserta

\section{SIMPULAN}

Pelatihan telah terselenggara dengan baik karena didukung penuh oleh pihak sekolah mitra, dimana semua guru menjadi peserta pelatihan dan mengikuti pelatihan hingga akhir. Peserta juga membawa laptop masing-masing sehingga bisa mengikuti latihan praktik. Walaupun ditemukan beberapa kendala teknis di lapangan, namun secara keseluruhan kegiatan pelatihan terbilang sukses serta mendapat apresiasi dari seluruh peserta.

Kegiatan pengabdian kepada masyarakat sebaiknya dilaksanakan secara kontinyu dengan bekerja sama dengan sekolah mitra. Pelatihan diselenggarakan secara sistematis 
dan sesuai dengan kebutuhan sekolah mitra dan menyediakan handout materi. Bahwa akan dipilih peserta pelatihan terbaik perlu diumumkan sejak awal pelatihan untuk menambah semangat para peserta pelatihan agar tetap fokus.

\section{DAFTAR PUSTAKA}

Lestari, S., dkk. (2015). Strategi Belajar dan Pembelajaran. Jakarta : Unindra Press.

Sanjaya, W. (2013). Strategi Pembelajaran Berorientasi Standar Proses Pendidikan. Jakarta : Kencana Prenadamedia Group. 